\title{
Poleward shift in the Southern Hemisphere westerly winds synchronous with the deglacial rise in $\mathrm{CO}_{2}$
}

WILLIAM R GRAY ${ }^{1}$, CASIMIR DELAVERGNE ${ }^{2}$, ROBERT CJ WILLS ${ }^{3}$, LAURIE MENVIEL ${ }^{4}$, PAUL SPENCE ${ }^{5}$, MARK HOLZER $^{6}$, MASA KAGEYAMA ${ }^{1}$ AND ELISABETH MICHEL $^{7}$

${ }^{1}$ Laboratoire des Sciences du Climat et de l'Environnement (LSCE/IPSL)

${ }^{2}$ LOCEAN Laboratory, Sorbonne Université-CNRS-IRD-MNHN

${ }^{3}$ Department of Atmospheric Sciences, University of Washington

${ }^{4}$ Climate Change Research Centre, University of New South Wales

${ }^{5}$ School of Geosciences, University of Sydney

${ }^{6}$ School of Mathematics and Statistics, University of New South Wales

${ }^{7}$ Laboratoire des Sciences du Climat et de l'Environnement (LSCE/IPSL), Gif-sur-Yvette

Presenting Author: william.gray@1sce.ipsl.fr

The Southern Hemisphere westerly winds influence deepocean overturning and carbon storage. While the westerly winds are hypothesised to play a key role in regulating atmospheric $\mathrm{CO}_{2}$ over glacial-interglacial cycles, past changes in their position remain poorly constrained. Here, we use a compilation of planktic foraminiferal $\delta^{18} \mathrm{O}$ from across the Southern Ocean and an ensemble of climate models to track changes in the latitude of the westerly winds over the last deglaciation. We find a $5 \pm 2^{\circ}(95 \% \mathrm{CI})$ equatorward shift in the westerlies during the Last Glacial Maximum ( 20,000 years ago) relative to the midHolocene $(\sim 6,000$ years ago). Our reconstruction shows that the poleward shift in the westerlies over the deglaciation closely mirrors the rise in atmospheric $\mathrm{CO}_{2}$. Using an eddy permitting ocean-sea-ice-carbon model we show that an equatorward shift in the westerlies substantially reduces the upwelling of deepwaters, leading to a suppression of $\mathrm{CO}_{2}$ outgassing from the Southern Ocean. Our results indicate a key role for the westerly winds in driving the deglacial rise in atmospheric $\mathrm{CO}_{2}$ and suggest that enhanced $\mathrm{CO}_{2}$ outgassing from the Southern Ocean is likely to act as a positive feedback as the westerlies shift poleward due to anthropogenic warming. 